УДК 657.631 (657.633.6)

\title{
ОСОБЕННОСТИ ПРОВЕДЕНИЯ АУДИТА ФИНАНСОВЫХ РЕЗУЛЬТАТОВ ДЕЯТЕЛЬНОСТИ ОРГАНИЗАЦИИ
}

\section{Лазарева Наталья Алексеевна}

к. э. Н., доцент

Майорова Екатерина Сергеевна

ЧОУ ВО «Санкт-Петербургский университет технологий управления и ЭКОНОМИКИ〉

Аннотация: В статье подробно освещена методика контроля финансовых результатов, с применением аудиторской деятельности. Приведены основные этапы аудиторской проверки. Рассмотрены информационно-компьютерные программы, применяемые для автоматизации аудиторской деятельности. Отражены проблемы, возникающие у аудитора, а также пути решения данных проблем.

Ключевые слова: аудит, контроль, аудиторский риск, система внутреннего контроля, планирование аудита, финансовый результат.

В современном мире для принятия обоснованного управленческого решения, пользователю необходимо владеть достоверной информацией. Поскольку неправильно заполненная отчетность, может нанести непоправимый вред организации и, следовательно, привести к убыткам. Предотвратить подобные последствия возможно, с помощью проведения аудиторской проверки.

Целью проверки финансовых результатов является установление соответствия применяемой предприятиями методики учета операций по формированию и использованию финансовых результатов нормативными документами [1, с.74-75]. Следовательно, отражение корректного финансового результата организации и соблюдения положений нормативных актов, является приоритетным, поскольку основным индикатором успешной деятельности компании по-прежнему остается ее финансовый результат.

Методика проведения аудиторской проверки включает в себя четыре основных этапа. Рассмотрим подробнее каждый из них (см. табл. 1). 


\section{Основные этапы аудиторской проверки}

\begin{tabular}{|l|l|}
\hline $1 . \quad$ Планирование & $\begin{array}{l}\text { Аудитор и клиент заключают договор. Далее аудитор } \\
\text { начинает расчёт уровня существенности, анализирует } \\
\text { систему бухгалтерского учета и СВК, затем рассчитывает } \\
\text { аудиторский риск, который напрямую влияет на объем и } \\
\text { порядок проведения аудиторских процедур }\end{array}$ \\
\hline $\begin{array}{l}2 . \quad \text { Сбор аудиторских } \\
\text { доказательств }\end{array}$ & $\begin{array}{l}\text { С учетом деятельности организации, аудитор } \\
\text { разрабатывает график и состав экспертов, участвующих в } \\
\text { проведении проверки. На выполнение поставленных задач } \\
\text { дается ограниченное количество времени. В рабочем } \\
\text { процессе план аудита допускает корректировки, а в } \\
\text { некоторых случаях полностью пересматриваться. }\end{array}$ \\
\hline 3. & Проведение аудита \\
& $\begin{array}{l}\text { Аудитор собирает, оценивает и анализирует } \\
\text { доказательства, на основании установленных стандартов и } \\
\text { нормативных документов. Главная цель данного этапа, } \\
\text { установление достоверности информации, а также } \\
\text { выяление недостоверной информации. }\end{array}$ \\
\hline 4. & Завершение аудита \\
& $\begin{array}{l}\text { Заказчик получает составленный аудитором отчет. С } \\
\text { помощью полученных данных компания разрабатывает ряд } \\
\text { действий направленные на усовершенствование системы } \\
\text { СВК и способствующих развитию компании. }\end{array}$ \\
\hline
\end{tabular}

В соответствии с Федеральным законом "Об аудиторской деятельности" от 30.12.2008 № 307-Ф3 [2], аудит - независимая проверка бухгалтерской (финансовой) отчетности аудируемого лица в целях выражения мнения о достоверности данных.

Объектами аудиторской проверки являются экономические системы, как отдельные, так и взаимосвязанные, показатели которых оцениваются количественно и качественно. Главным объектом выступает финансовый результат деятельности компании.

Финансовый результат - это выраженный в денежной форме экономический результат деятельности предприятия, объединения, организации в целом и ее отдельных подразделений [3, с.495].

Задачами аудита финансовых результатов является проверка достоверности финансовых результатов организации, выявление возможных ошибок, допущенных бухгалтером, проверка учета операционных внереализационных доходов и расходов, а также проверка отражения нераспределенной (чистой) прибыли организации. 
Планирование включает в себя тестирование СВК (средств внутреннего контроля), с последующим определением аудиторского риска, и разработку программы аудита, на основании первичной документации.

Аудитор определяет какие группы доходов учитывать, на основании уровня существенности, оценки СВК и бухгалтерского учета. С помощью этих показателей определяется и метод проверки.

Всего существует три метода проверки: сплошной, выборочный, и комбинированный. Рассмотрим подробнее каждый из них.

Сплошной метод проверки представляет собой подробное изучение первичной документации, включая сверку первичной бухгалтерской документации с регистрами аналитического учета, и последующим сопоставлением полученных данных с оборотами по счетам синтетического учета. В заключении аудитор проверяет правильность отражения остатков по синтетическим счетам на отчетную дату.

Основой выборочного метода является репрезентативная выборка. С помощью данного метода становится возможным не нарушая стандарты аудиторской деятельности, получать полные и достоверные данные, проверяя бухгалтерскую отчетность в выборочном порядке. Аудитор определяет допустимый риск и отражает анализ выборки в отчете.

Комбинированный метод проверок сочетает в себе как сплошной, так и выборочный метод. Для аудита незначительного объема данных с высоким риском применяется сплошной метод (расчетно-кассовые, хозяйственные операции).

Перед началом проверки, аудитору необходимо предоставить для ознакомления бухгалтерский баланс и отчет о финансовых результатах, а также отчет о движении денежных средств, что позволит аудитору оценить финансовое состояние организации, и эффективность производства [4, с. 408].

При проведении аудиторской проверки, аудитору следует обратить внимание на установление последовательности включения этапов аудиторской проверки в контрольный процесс, руководствуясь нормативными законодательными и методическими актами. Следовательно, методика проведения аудита финансовых результатов представляет собой деятельность, в состав которой входят взаимосвязанные между собой процессы (рис. 1). 


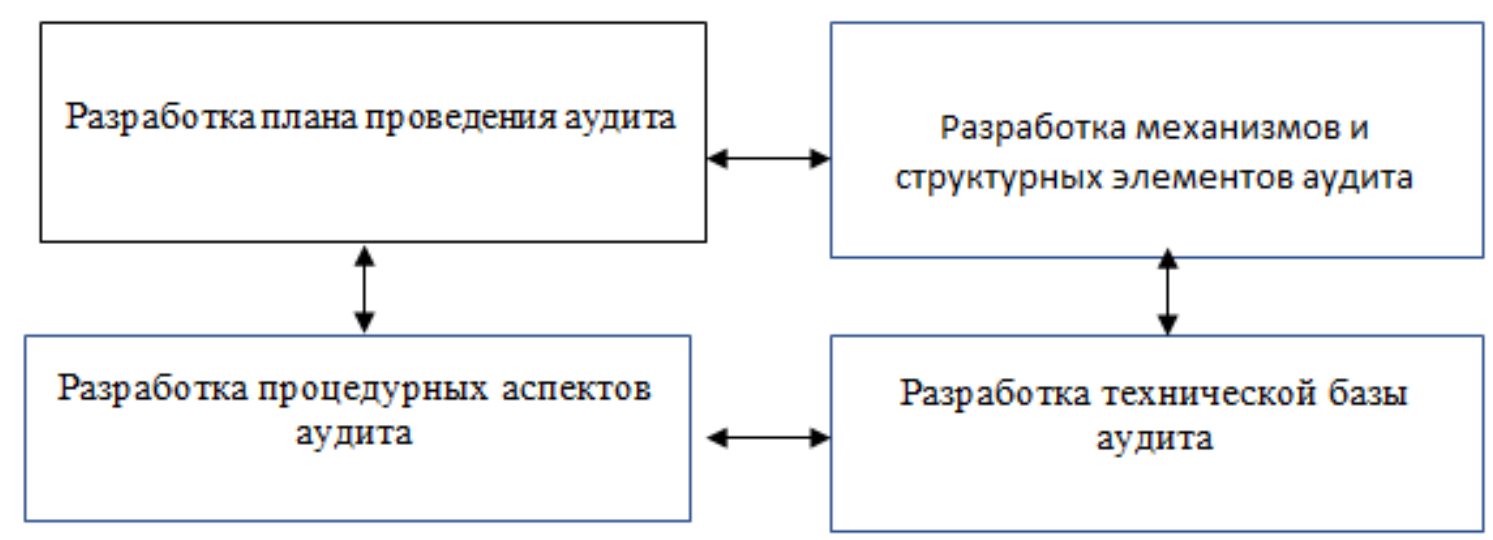

\section{Рисунок 1. Методика проведения аудита финансовых результатов}

Для автоматизации аудиторской проверки применяются компьютерные информационные программы, такие как, «IT Audit: Аудитор»; «Audit Expert»; «Экспресс Аудит: ПРОФ»; «Case Ware Working Papers» и др. (табл. 2).

Таблица 2

Компьютерные информационные программы, применяемые при проведении аудита финансовых результатов

\begin{tabular}{|c|c|}
\hline $\begin{array}{c}\text { Наименование } \\
\text { программы }\end{array}$ & Характеристика \\
\hline IT Audit: Аудитор & $\begin{array}{l}\text { Отечественная программа, предназначенная для автоматизации } \\
\text { аудиторской деятельности, программа применяется при } \\
\text { проведении внутреннего аудита компании, оценке рисков, а } \\
\text { также проведении финансового аудита. Преимуществом } \\
\text { продукта является модуль «Методолог», позволяющий создать } \\
\text { собственную (индивидуальную) методику на базе методики } \\
\text { основной программы IT Audit }\end{array}$ \\
\hline Audit Expert & $\begin{array}{l}\text { Российская программа, применяемая для оценки и мониторинга } \\
\text { финансового состояния предприятия. Audit Exреrt имеет } \\
\text { широкий спектр функциональных возможностей, как экспресс } \\
\text { анализ финансового состояния, так и коэффициентный. С } \\
\text { помощью скрининга становится возможным оценить } \\
\text { кредитоспособность заемщика, а также проанализировать } \\
\text { операционные и финансовые риски. Продукт выпускается в } \\
\text { двух версиях Standard и Professional. Активно используется в } \\
\text { крупных организациях, госорганах, аудиторских фирмах }\end{array}$ \\
\hline Экспресс Аудит: & Программа предназначена для решения основных задач, \\
\hline
\end{tabular}




\begin{tabular}{|c|l|}
\hline \multicolumn{1}{|c|}{ ПРОФ } & $\begin{array}{l}\text { возникающих при проведении аудиторской проверки } \\
\text { финансовых результатов коммерческой организации. От этапа } \\
\text { планирования до заключительного этапа формирования } \\
\text { аудиторского заключения }\end{array}$ \\
\hline Case Ware Working & $\begin{array}{l}\text { Это зарубежная программа, которая позволяет } \\
\text { автоматизировать работу с большим объемом данных, } \\
\text { обеспечивает возможность создания централизованной } \\
\text { системы управления данными, а также оптимизирует } \\
\text { проектную работу, в соответствии с стандартами МСФО. } \\
\text { Продукт интегрируется с другими программами, архивирует } \\
\text { электронные файлы, имеется электронный обзор и мониторинг }\end{array}$ \\
\hline
\end{tabular}

К основным проблемам аудита финансовых результатов можно отнести халатный подход к процедуре проведения аудиторской проверки, отсутствие индивидуального подхода в процессе проведения аудита, а также в случае отсутствия у аудитора полной достоверной информации о деятельности организации. В качестве решения возникающих проблем предлагается начать разработку системы расчета общей стоимости услуг аудиторской деятельности, включая повышение уровня качества оказываемых аудиторских услуг, за счет введения дополнительных требований к квалификации и качеству проведения аудиторской проверки финансовых результатов, в соответствии с международными стандартами проведения аудита.

В заключении следует отметить, что для достижения положительных результатов, организации следует контролировать и своевременно проводить аудиторскую проверку.

\section{Список литературы}

1. Изотова, Л. К. Аудит обязательный и по собственному желанию. / Л. К. Изотова // Расчет — 2006 - № 2-74-75 c.

2. Постановления Правительства Российской Федерации. Об утверждении федеральных правил (стандартов) аудиторской деятельности от 23.09.2002 № 696. [Электронный ресурс]. - Режим доступа: http://www.consultant.ru/online/base/? req=doc;base=LAW;n=109853

3. Райзберг Б. А., Лозовский Л. Ш., Стародубцева Е. Б. Современный экономический словарь. - 5-е издание, перераб. и доп. - М.: ИНФА-М, 2006.$495 \mathrm{c}$

4. Утенкова Е. А. Аудит: учеб.пособ. / Е. А. Утенкова. - М.: Алерта, 2011. $-408 \mathrm{c}$. 